\title{
Analysis and Implementation of a Novel Asymmetrical Half-Bridge High Step-Down DC-DC Converter
}

\author{
*Sung-Pei Yang, Shin-Ju Chen, Chao-Ming Huang and Bo-Kai Chiou \\ Department of Electrical Engineering, Kun Shan University, \\ No.195, Kunda Rd., Tainan City 710, Taiwan, R.O.C. \\ *Corresponding Author: spyang@mail.ksu.edu.tw
}

\begin{abstract}
A novel asymmetrical half-bridge high step-down (AHB-HSD) dc-dc converter is proposed in this paper. A buck inductor is applied to the conventional asymmetrical half-bridge step-down (AHB-SD) dc-dc converter to achieve the high step-down voltage conversion. Moreover, all switches of the proposed converter can achieve zero-voltage switching (ZVS) under turn-on transition. The operating principle of the proposed converter is presented in detail herein to prove the aforementioned results. Finally, a $400 \mathrm{~V}$ input voltage, $48 \mathrm{~V}$ output voltage, $400 \mathrm{~W}$ output power prototype of proposed converter is implemented. The theoretical analysis is thus verified by experimental results. The maximum power efficiency of the proposed converter is $89.8 \%$ at output power of $250 \mathrm{~W}$.
\end{abstract}

Keywords: asymmetrical half-bridge (AHB), high step-down (HSD), zero-voltage switching (ZVS).

\section{Introduction}

A power supply for telecom equipments and modern computers is required to have the characteristic of high power density, which can be achieved by operating at a higher switching frequency. It is well known that the switching losses increase and the efficiency decreases with increasing switching frequency. To overcome this drawback, the soft switching techniques are taken into consideration (1-7). As a result, a conventional asymmetrical half-bridge step-down (AHB-SD) dc-dc converter as shown in Fig. 1 is usually used to obtain zero-voltage switching (ZVS) operation at turn-on transition and low voltage stress for all the switches (5-7). Its output voltage can be determined by the conversion ratio $V_{o} / V_{\text {in }}=D(1-D) / n$. However, for increasing the step-down conversion ratio with high output current rating applications, one is to get extremely narrow duty cycle, the other is to have a higher turns ratio $n$ of the transformer. Unfortunately, an extremely narrow duty cycle is difficultly controlled to regulate the output voltage. Moreover, the noise is easily affected the narrow duty cycle to cause the converter out of order. To avoid the narrow duty cycle in the high step-down conversion, a higher turns ration $n$ is thus applied to the transformer of the conventional AHB-SD converter. However, the higher turns ratio will increase the inter-winding capacitances, winding resistances and leakage inductances. It thereby complicates the design and implementation of the transformer. The volume of transformer also becomes large and decreases the power density of the converter.

To solve this problem, many high step-down techniques are thus presented in the literature (8-11). Consequently, a novel asymmetrical half-bridge high step-down (AHB-HSD) dc-dc converter depicted in Fig 2 is proposed by applying a buck inductor $L_{b}$ to connect with the rectifier diode $D_{1}$. The proposed converter exhibits significant advantages of high step-down conversion ratio, ZVS operation and low voltage stress for all switches, no extremely narrow duty cycle and low turns ratio $n$ of transformer.

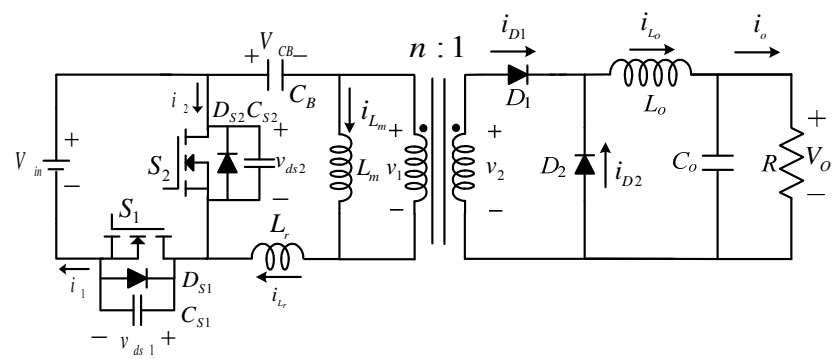

Fig. 1. Conventional AHB-SD converter. 


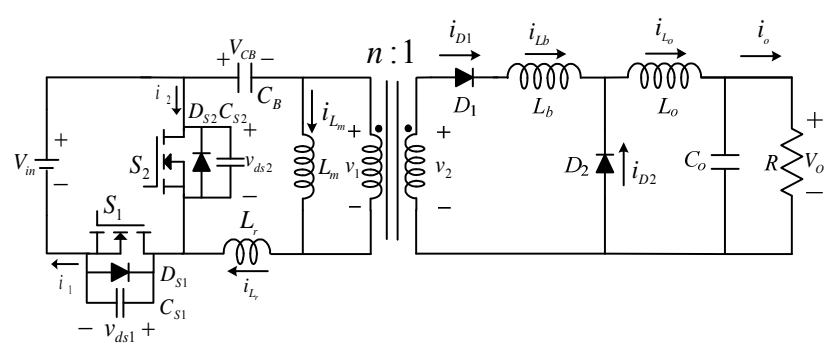

Fig. 2. Proposed AHB-HSD converter.

\section{Operating Principle}

The proposed asymmetrical half-bridge high step-down (AHB-HSD) converter presented in Fig. 2 contains two main switches $S_{1}, S_{2}$, which are driven complementarily with two small dead bands to realize the ZVS at turn-on operation for each main switch.

Some assumptions are made as follows before describing the operating principle of the proposed AHBHSD converter.

1) All switches and diodes of the proposed converter are ideal. The switching time of the switches and the reverse recovery time of the diodes can be neglected.

2) Because the time intervals of the resonance, the charge and discharge time of capacitors $C_{S 1}$ and $C_{S 2}$ are much smaller than switching period $T_{S}$, the inductor current $i_{L o}$ are considered as constants $i_{L o}^{\max }$ during the turn-off transition for switch $S_{1}$, and $i_{L o}^{\text {min }}$ during the turn-on transition for switch $S_{1}$, respectively.

3) The block capacitance $C_{B}$ and output capacitance $C_{o}$ are large enough so that their voltages are regarded as constant voltages $V_{C B}$ and $V_{o}$, respectively.

4) The equivalent inductance is

$$
L_{e}=L_{m} / /\left(L_{b}+L_{o}\right)=\frac{L_{m}\left(L_{b}+L_{o}\right)}{L_{m}+L_{b}+L_{o}}
$$

where $L_{r}<<L_{e}, L_{e}<L_{m}$ and $L_{e}<L_{b}+L_{o}$.

5) The turns ratio $n$ of the transformer is 1 .

Based on the switching of the switches and diodes, the proposed converter operating over one switching period $T_{S}$ can be divided into ten linear stages described as follows. The equivalent circuit of each stage is presented in Fig. 3.
Stage $1\left[t_{0}, t_{1}\right]\left(\boldsymbol{S}_{1}\right.$ : off, $\boldsymbol{S}_{2}$ : off, $\boldsymbol{D}_{S 1}$ : off, $\boldsymbol{D}_{S 2}$ : off, $\boldsymbol{D}_{1}$ : on, $D_{2}:$ off)

Before time $t_{0}$, the switches $S_{1}$ and $S_{2}$ are on and off, respectively. The circuit operation has been achieved steady state. When the switch $S_{1}$ is turned off at time $t_{0}$, this stage starts. In this stage, the capacitor $C_{S 1}$ are charged linearly by constant current $i_{1}\left(t_{0}\right)$, and the capacitor $C_{S 2}$ is discharged linearly by constant current $i_{2}\left(t_{0}\right)$. Notably, the currents $i_{1}$ and $i_{2}$ are satisfied the equality of $i_{L r}=i_{1}+i_{2}$. When the voltage $v_{d s 1}$ increases to $V_{i n}-V_{C B}+L_{b} V_{o} / L_{o}$ and voltage $v_{d s 2}$ drops to $V_{C B}-L_{b} V_{o} / L_{o}$, the diode $D_{2}$ thereby conducts and this stage ends.

Stage $2\left[t_{1}, t_{2}\right]\left(\boldsymbol{S}_{1}\right.$ :off, $\boldsymbol{S}_{2}$ : off, $\boldsymbol{D}_{S 1}$ : off, $\boldsymbol{D}_{S 2}$ : off, $\boldsymbol{D}_{1}$ : on, $D_{2}:$ on)

As the diode $D_{2}$ conducts, the resonance between $\left(L_{r}+L_{b} / / L_{m}\right)$ and $\left(C_{S 1}+C_{S 2}\right)$ is occurred. When the voltage $v_{C_{S 1}}$ is charged to $V_{i n}$, and the voltage $v_{d s 2}$ is discharge to zero simultaneously. In the meanwhile, the diode $D_{S 2}$ starts to conduct and the resonance is stopped. This stage is thus finished.

Stage $3\left[t_{2}, t_{3}\right]\left(S_{1}\right.$ : off, $S_{2}$ : off, $D_{S 1}$ : off, $D_{S 2}:$ on, $D_{1}:$ on, $D_{2}$ : on )

As the diode $D_{S 2}$ is forward-biased, the voltage $v_{d s 2}$ is clamped at zero. The switch $S_{2}$ can be thereby turned on under ZVS operation. Because the voltage across to the equivalent inductor $\left(L_{r}+L_{b} / / L_{m}\right)$ is $-V_{C B}$, the inductor currents $i_{L r}, i_{L m}$ and $i_{L b}$ thus decreases linearly. As the inductor current $i_{L b}$ falls to zero, the diode $D_{1}$ becomes reverse-biased and this stage ends. To ensure the ZVS operation for the switch $S_{2}$, the inductor current $i_{L_{r}}$ is still positive at the end of this stage.

Stage $4\left[t_{3}, t_{4}\right]\left(S_{1}:\right.$ off, $S_{2}:$ on, $D_{S 1}$ : off, $D_{S 2}:$ on, $D_{1}$ : off, $D_{2}$ : on )

Since the $D_{1}$ is off, the voltage $-V_{C B}$ is thus across to the inductors $L_{m}$ and $L_{r}$. Therefore, the inductor currents $i_{L r}$ and $i_{L m}$ still linearly decrease. As the inductor current $i_{L r}$ falls to zero, the diode $D_{S 2}$ becomes off and this stage ends.

Stage $5\left[t_{4}, t_{5}\right]\left(S_{1}\right.$ : off, $S_{2}$ : on, $D_{S 1}$ : off, $D_{S 2}$ : off, $D_{1}$ : off, $D_{2}:$ on)

In this stage, the circuit operation is similar to the $S_{1}$ turn-off state of a conventional AHB-SD converter. 


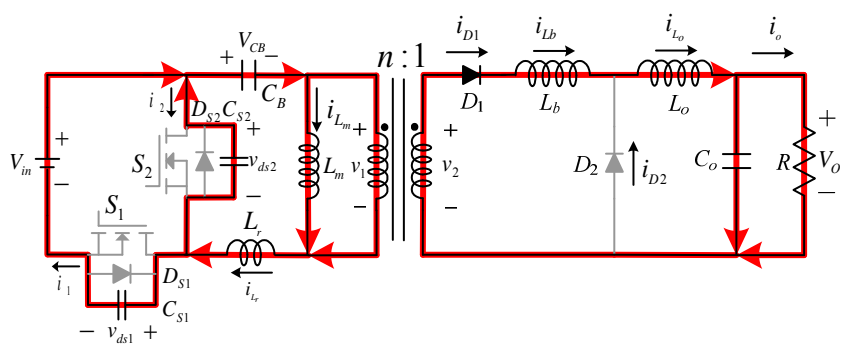

(a) Stage $1:\left[t_{0}, t_{1}\right]$

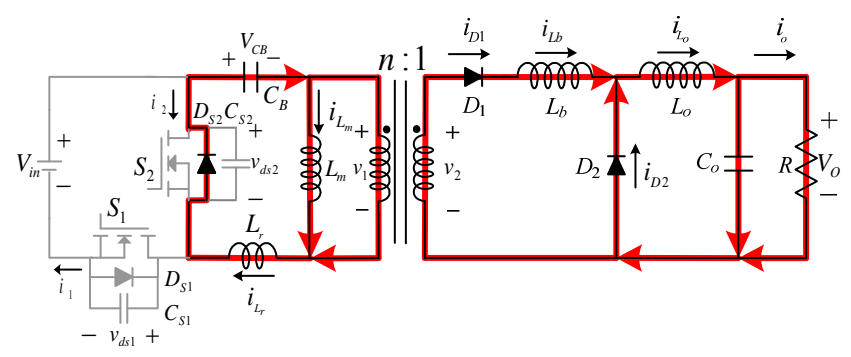

(c) Stage $3:\left[t_{2}, t_{3}\right]$

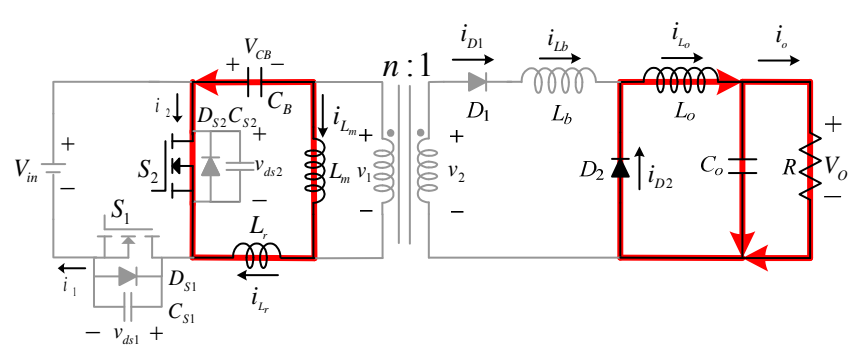

(e) Stage $5:\left[t_{4}, t_{5}\right]$

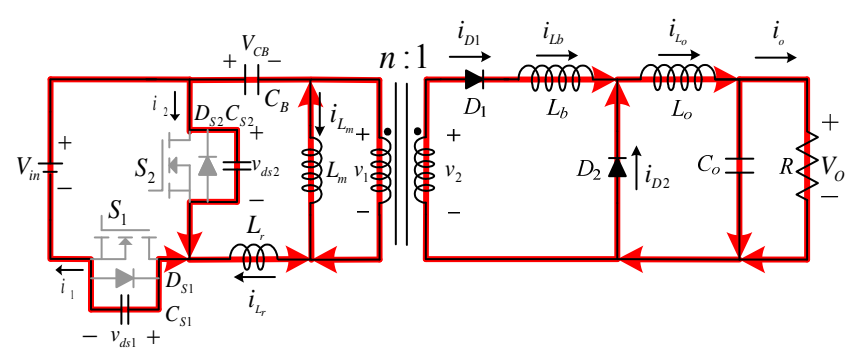

(g) Stage $7:\left[t_{6}, t_{7}\right]$

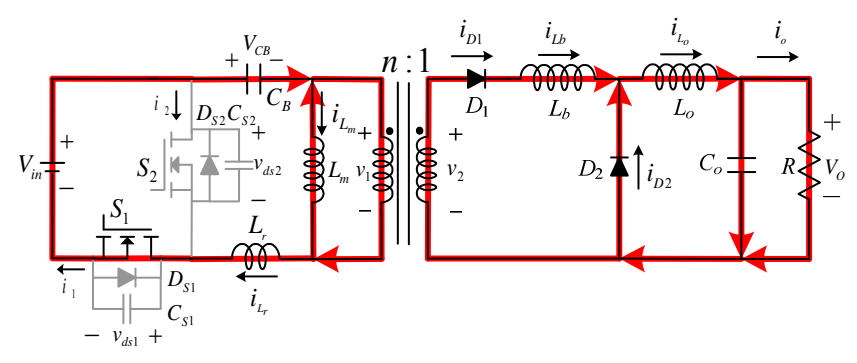

(i) Stage $9:\left[t_{8}, t_{9}\right]$

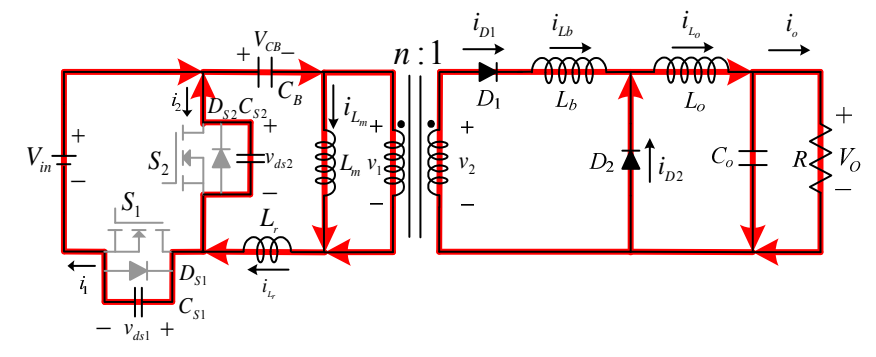

(b) Stage $2:\left[t_{1}, t_{2}\right]$

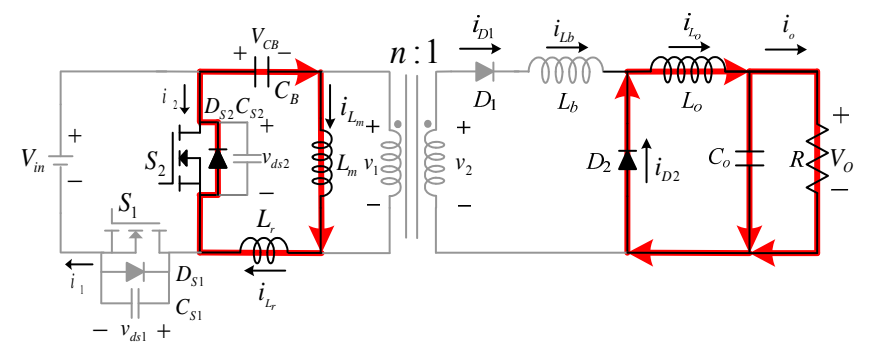

(d) Stage $4:\left[t_{3}, t_{4}\right]$

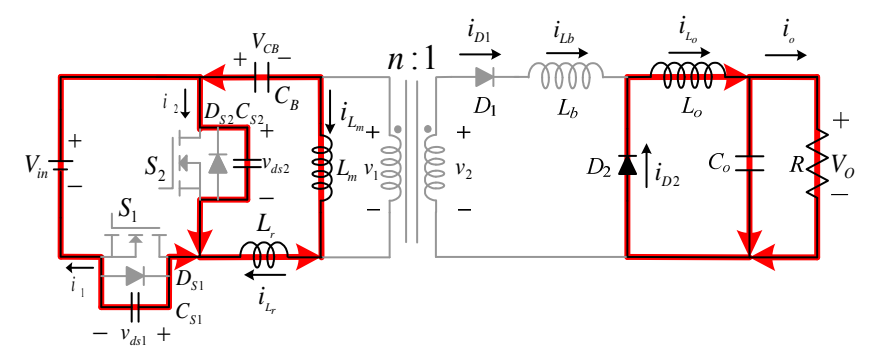

(f) Stage $6:\left[t_{5}, t_{6}\right]$

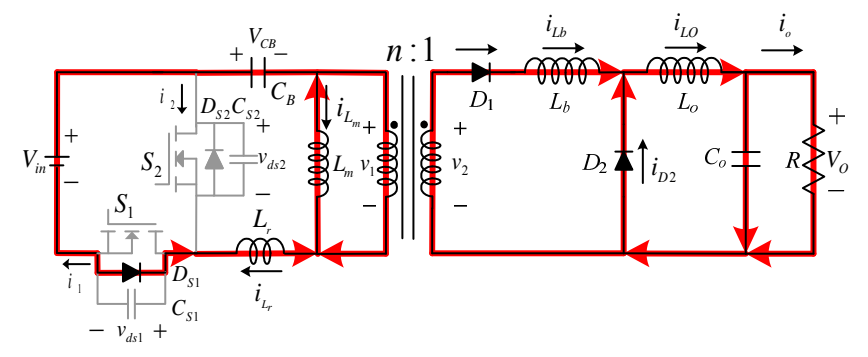

(h) Stage $8:\left[t_{7}, t_{8}\right]$

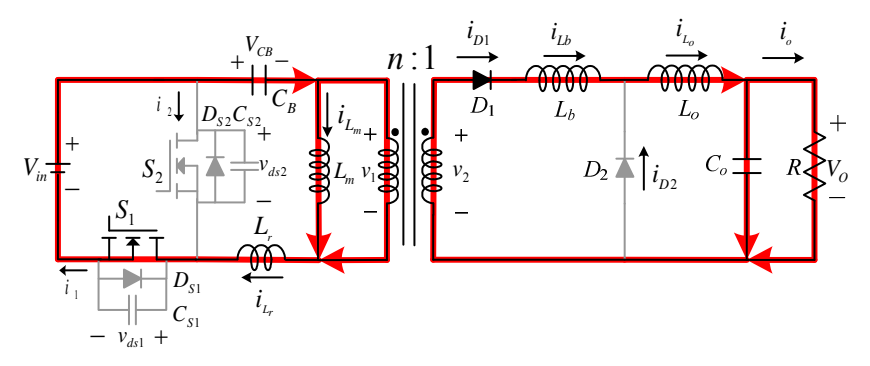

(j) Stage $10:\left[t_{9}, t_{0}+T_{s}\right]$

Fig. 3. Equivalent circuit of each linear stage. 
Stage $6\left[t_{5}, t_{6}\right]\left(\boldsymbol{S}_{1}\right.$ : off, $\boldsymbol{S}_{2}$ : off, $\boldsymbol{D}_{S 1}$ : off, $\boldsymbol{D}_{S 2}$ : off, $\boldsymbol{D}_{1}$ : off, $D_{2}:$ on)

At time $t_{5}$, the switch $S_{2}$ is turned off and thus this stage begins. In this stage, the capacitor $C_{S 1}$ are discharged linearly by constant current $-i_{1}\left(t_{5}\right)$, and the capacitor $C_{S 2}$ is discharged linearly by constant current $-i_{2}\left(t_{5}\right)$. When the voltage $v_{d s 1}$ decreases to $V_{i n}-V_{C B}$ and voltage $v_{d s 2}$ rises to $V_{C B}$, the diode $D_{1}$ thereby conducts and this stage ends.

Stage $7\left[t_{6}, t_{7}\right]\left(\boldsymbol{S}_{1}\right.$ : off, $\boldsymbol{S}_{2}$ : off, $\boldsymbol{D}_{S 1}$ : off, $\boldsymbol{D}_{S 2}$ : off, $\boldsymbol{D}_{1}:$ on, $D_{2}:$ on)

As the diode $D_{1}$ conducts, the resonance between $\left(L_{r}+L_{b} / / L_{m}\right)$ and $\left(C_{S 1}+C_{S 2}\right)$ is occurred. The inductor current $i_{L b}$ thus rises by the resonance from zero. When the voltage $v_{d s 1}$ is discharged to zero, and the voltage $v_{d s 2}$ is charge to $V_{\text {in }}$ simultaneously. In the meanwhile, the diode $D_{S 1}$ starts to conduct and the resonance is stopped. This stage is thus finished.

Stage $8\left[t_{6}, t_{7}\right]\left(S_{1}:\right.$ off, $S_{2}:$ off, $D_{S 1}:$ on, $D_{S 2}:$ off, $D_{1}:$ on, $D_{2}:$ on )

As the diode $D_{S 1}$ conducts, the voltage $v_{C_{S 1}}$ is clamped at zero. The switch $S_{1}$ can be thereby turned on under ZVS operation. Because the voltage across to the equivalent inductor $\left(L_{r}+L_{b} / / L_{m}\right)$ is $V_{i n}-V_{C B}$, the inductor currents $i_{L r}, i_{L m}$ and $i_{L b}$ thus increases linearly. As the inductor current $i_{L r}$ rises to zero, the diode $D_{S 1}$ thus becomes off and this stage ends. To ensure the ZVS operation for the switch $S_{1}$, the switch $S_{1}$ must turn on before the inductor current $i_{L r}$ becomes positive.

Stage $9\left[t_{8}, t_{9}\right]\left(\boldsymbol{S}_{1}:\right.$ on, $\boldsymbol{S}_{2}:$ off, $\boldsymbol{D}_{S_{1}}$ : off, $\boldsymbol{D}_{\mathrm{S} 2}$ : off, $\boldsymbol{D}_{1}$ : on, $D_{2}:$ on)

In this stage, the inductor currents $i_{L r}, i_{L m}$ and $i_{L b}$ still rise linearly. As the inductor current $i_{L b}$ rises to $i_{L o}^{\min }$, the diode $\mathrm{D}_{2}$ thus conducts and this stage ends.

Stage $10\left[t_{9}, t_{0}+T_{s}\right]\left(\boldsymbol{S}_{1}:\right.$ on, $\boldsymbol{S}_{2}$ : off, $\boldsymbol{D}_{\mathbf{S 1}}$ : off, $\boldsymbol{D}_{\mathbf{S} 2}$ : off, $\boldsymbol{D}_{\mathbf{1}}$ : on, $D_{2}$ : on)

In this stage, the circuit operation is similar to the $S_{1}$ turn-on state of a conventional AHB-SD converter.

The next switching period starts when $S_{1}$ is turned off again. According to the aforementioned operating principle of the proposed converter, the key waveforms over one switching period $T_{S}$ are schematically depicted in Fig. 4.

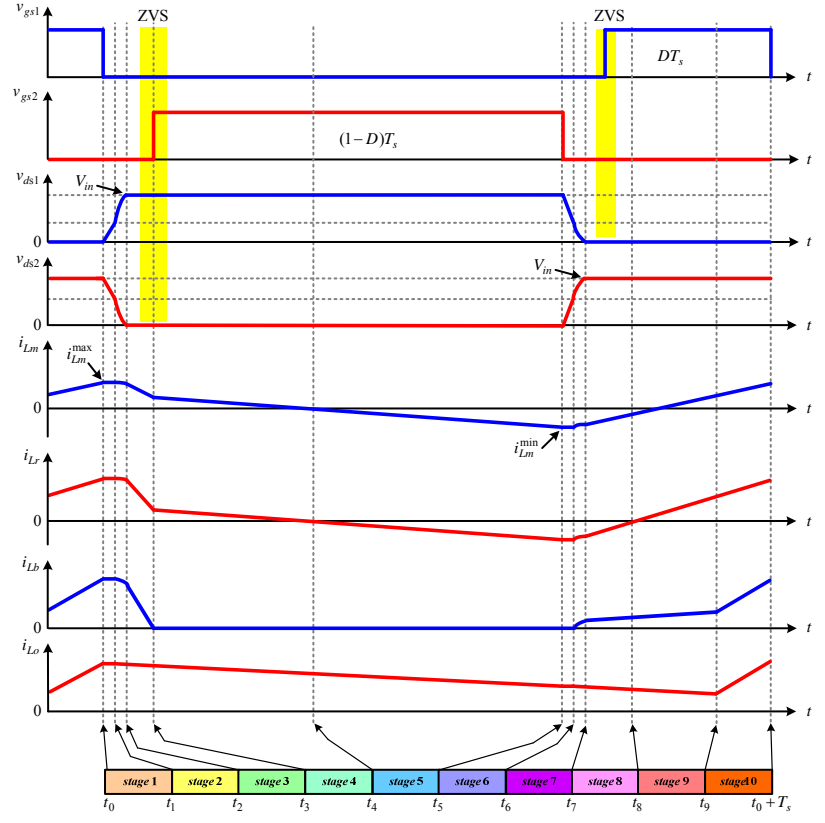

Fig.4. Key waveforms over one switching period $T_{s}$.

Neglecting the dead times for brief steady-state analysis, the duty cycles of main switches $S_{1}$ and $S_{2}$ will thus be $D$ and $1-D$, respectively. In the steady state, based on the voltage-second balance principle to the magnetizing inductor $L_{m}$, it shows that voltage $V_{C B}$ is a function as

$$
V_{C B}=g\left(V_{i n}, D, k, R\right)
$$

where $k=T_{9} / T_{s}$. Moreover, at the end of the stage 9 , the inductor current $i_{L a}$ must reach the current $i_{L o}^{\min }$. It gives

$$
\frac{V_{\text {in }}-V_{C B}}{L_{b}+L_{r}} T_{9}=\frac{V_{o}}{R}-\frac{1}{2} \frac{V_{o}}{L_{o}}\left((1-D) T_{s}+T_{9}\right) \text {. }
$$

Similarly, according to the voltage-second balance principle to the output inductor $L_{o}$, we thus have

$\frac{V_{o}}{L_{o}}\left((1-D) T_{s}+T_{9}\right)=\frac{1}{L_{b}+L_{o}}\left(V_{i n}-V_{C B}-V_{o}\right)\left(D T_{s}-T_{9}\right)$.

Solving equations (3) and (4), thus it yields

$$
V_{o}=f\left(V_{\text {in }}, D, k, R\right)
$$

where $f\left(V_{i n}, D, k, R\right)$ is a function of variables $V_{\text {in }}, D$, $k$ and $R$.

\section{Experimental Results}

For $400 \mathrm{~V}$ input and $48 \mathrm{~V} 400 \mathrm{~W}$ output, a prototype of the proposed AHB-HSD converter, operating at $100 \mathrm{kHz}$, is implemented. Based on the experimental results, the 
soft-switching performance of all the switches and the high power efficiency of the proposed converter can thus be validated. The power specifications and component parameters are listed in Table 1.

Table 1. Power specifications and component parameters.

\begin{tabular}{|c||c||c||c||}
\hline$V_{\text {in }}$ & $400 \mathrm{~V}$ & $V_{o}$ & $48 \mathrm{~V}$ \\
\hline \hline$P_{o}$ & $100 \sim 400 \mathrm{~W}$ & $f_{S}$ & $100 \mathrm{kHz}$ \\
\hline \hline$n$ & 1 & $L_{m}$ & $302 \mu \mathrm{H}$ \\
\hline \hline$L_{b}$ & $4 \mu \mathrm{H}$ & $L_{o}$ & $207 \mu \mathrm{H}$ \\
\hline$C_{B}$ & $33 \mu \mathrm{F}$ & $L_{r}$ & $25 \mu \mathrm{H}$ \\
\hline \hline$C_{S 1}, C_{s 2}$ & $1250 \mathrm{pF}$ & $C_{o}$ & $1000 \mu \mathrm{F}$ \\
\hline \hline
\end{tabular}

\subsection{Steady-state characteristic}

It reveals from Fig. 5 that the input voltage $V_{\text {in }}$ is $400 \mathrm{~V}$ and the output voltage $V_{o}$ is $48 \mathrm{~V}$ at full load. Moreover, according to the gating signal $v_{g s 1}$ of the experimental result in Fig. 5, we have the duty cycle $D=0.46$, which is not a narrow duty cycle. However, for the conventional AHB-SD converter, its output voltage $V_{o}$ is $99.3 \mathrm{~V}$ with $D=0.46$ and $n=1$, which is much larger than $48 \mathrm{~V}$.

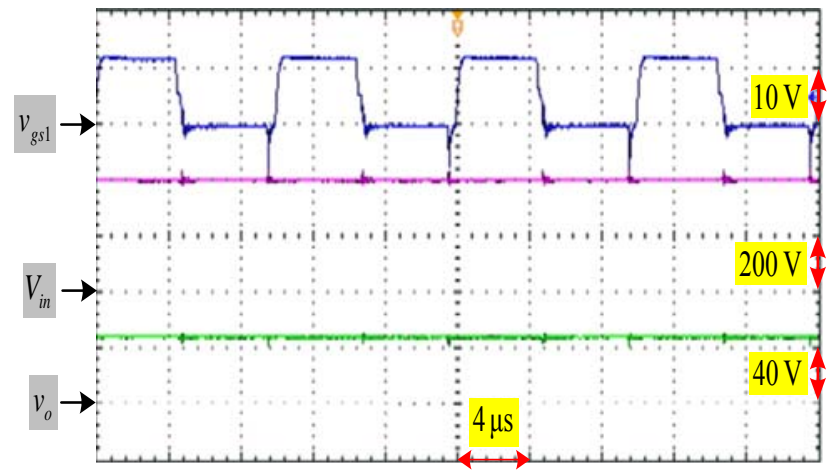

Fig. 5. Waveforms of gating signal $v_{g s 1}$, input voltage $V_{\text {in }}$ and output voltage $V_{o}$ at full load.

On the other hand, it reveals from Fig. 6 that the experimental result of $V_{C B}=223 \mathrm{~V}$ at full load. Moreover, it is seen from the Fig. 7 that the current $i_{L o}$ does not star to rise immediately as the switch $S_{1}$ turns on. When the inductor current $i_{L b}$ rises to $i_{L o}^{\min }$, the diode $D_{2}$ thus becomes reverse-biased and the currents $i_{L b}$ and $i_{L o}$ increase with the same slop. Since the switch $S_{1}$ turns off, the currents $i_{L b}$ and $i_{L o}$ begin to drop with different slop. The current $i_{L b}$ will fall to zero in one switching period.

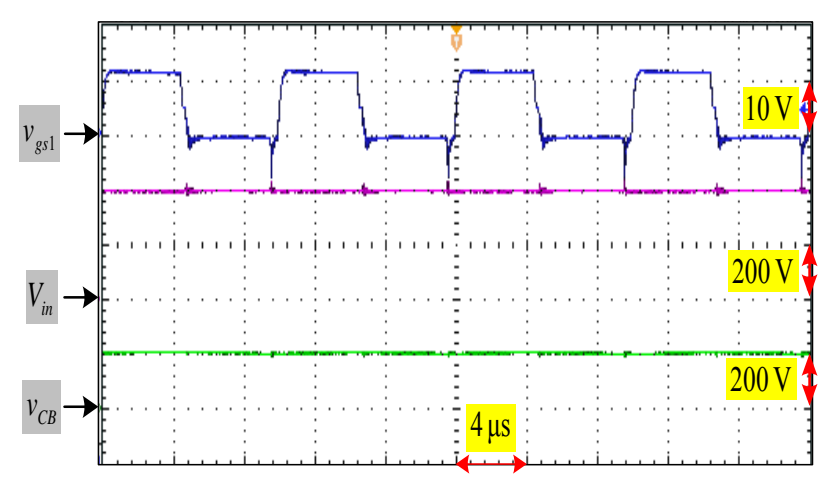

Fig. 6. Waveforms of gating signal $v_{g s 1}$, input voltage $V_{\text {in }}$ and capacitor voltage $V_{C B}$ at full load.

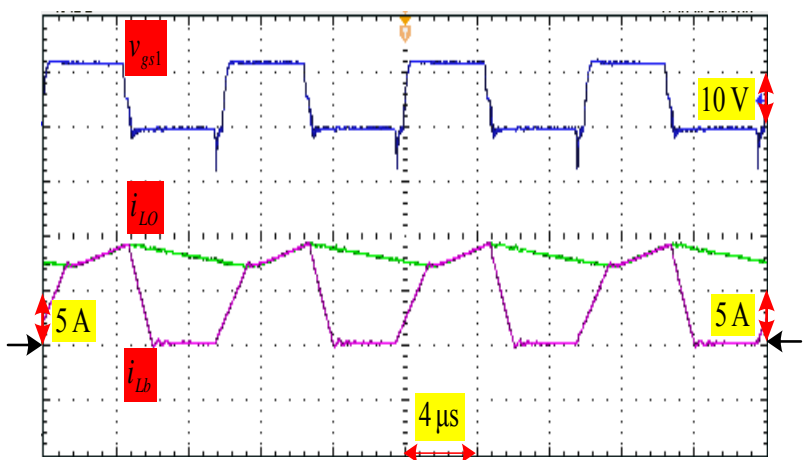

Fig. 7. Waveforms of gating signal and drain-to-source voltage of switch $S_{2}$ at full load.

\subsection{Soft-switching performance}

Figs. 8-9 show the experimental results of gating signals and drain-to-source voltages of all the switches. It reveals that the switches are turned on after their drain-to-source voltages drop to zero. As a result, all the switches of the proposed converter are achieved ZVS operation at turn-on transition. Moreover, we also can find that the maximum voltages across switches $S_{1}$ and $S_{2}$ are nearly input voltage $V_{\text {in }}=400 \mathrm{~V}$.

\subsection{Power efficiency measurement}

Figure 10 shows the measured efficiency versus various output power. The efficiency at different load conditions is also listed in the Table 2. The highest efficiency of the proposed converter is about $89.8 \%$. The efficiency $82.4 \%$ of the proposed converter at full load of $400 \mathrm{~W}$ can be further improved by using synchronous rectification.

Table 2. Measured efficiency at various output power.

\begin{tabular}{|l|l|l|l|l|l|l|l|}
\hline $\begin{array}{l}\text { Output power } \\
(\mathrm{W})\end{array}$ & 100 & 150 & 200 & 250 & 300 & 350 & 400 \\
\hline Efficiency(\%) & 86.7 & 88.6 & 89.5 & 89.8 & 89.1 & 86.7 & 82.4 \\
\hline
\end{tabular}




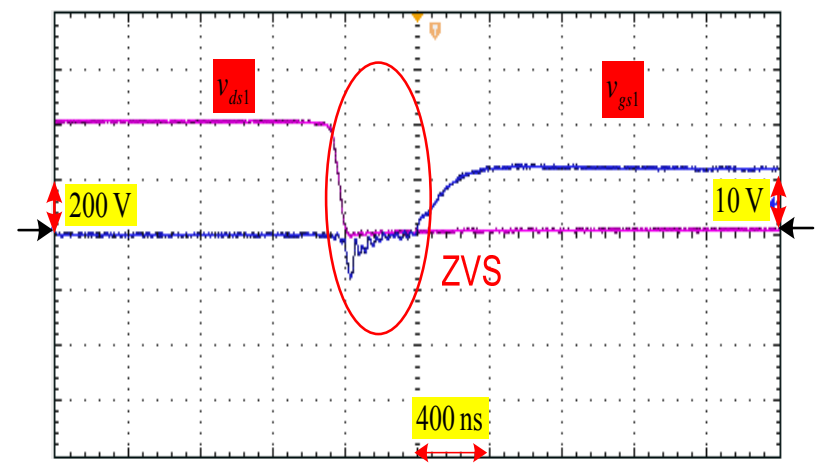

Fig. 8. Waveforms of gating signal $v_{g s 1}$ and drain-to-source voltage $v_{d s 1}$ of switch $S_{1}$ at full load.

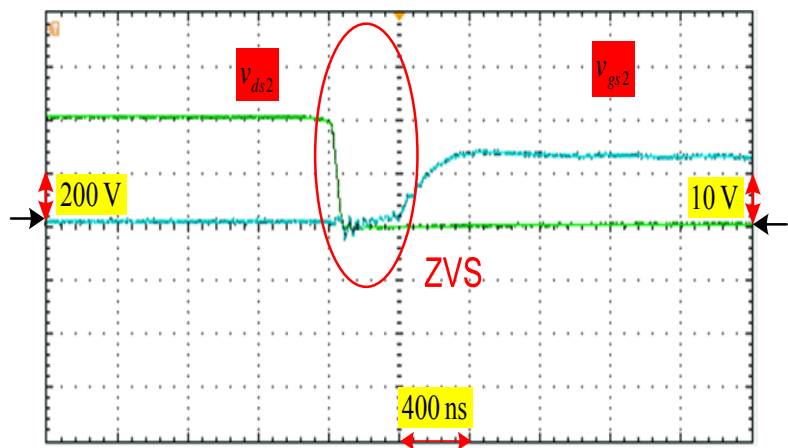

Fig. 9. Waveforms of gating signal $v_{g s 2}$ and drain-to-source voltage $v_{d s 2}$ of switch $S_{2}$ at full load.

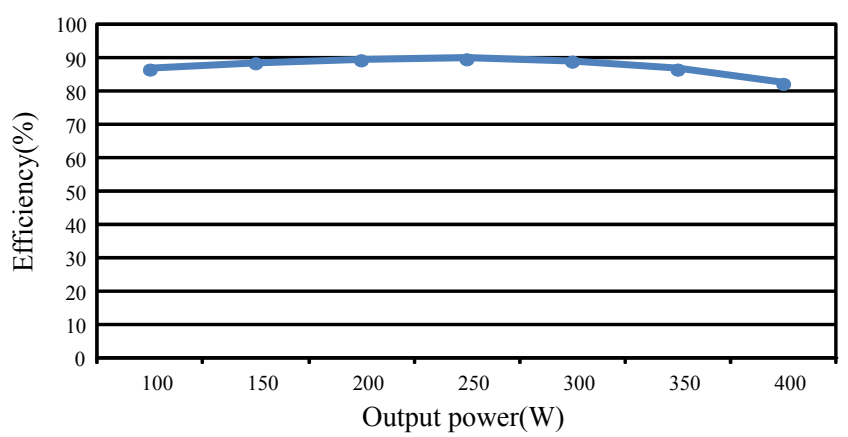

Fig. 10. Measured efficiency versus various output power.

\section{Conclusions}

An asymmetrical half-bridge high step-down dc-dc converter is proposed to achieve high step-down voltage conversion and ZVS operation under turn-on transition for all switches. The voltage stress across the two main switches is the input voltage $V_{i n}=400 \mathrm{~V}$. It means that the switches do not have the problem of high voltage stress. Furthermore, the experimental results of a prototype with $400 \mathrm{~V}$ input and $48 \mathrm{~V} / 400 \mathrm{~W}$ output thereby are presented to validate the theoretical analysis and ZVS performance of the proposed converter. The measured maximum power efficiency of the proposed converter is $89.8 \%$ at output power of $250 \mathrm{~W}$.

\section{Acknowledgment}

The authors would like to thank the Ministry of Science and Technology, Taiwan, for supporting this research under Contract No. MOST 104-2221-E-168-009.

\section{References}

(1) Q. M. Li and F. C. Lee, "Design consideration of the active-clamp forward converter with current mode control during large-signal transient," IEEE Trans. Power Electron., Vol. 18, No. 4, pp. 958-965, 2003

(2) T. Qian and B. Lehman, "Dual interleaved active-clamp forward with automatic charge balance regulation for high input voltage application," IEEE Trans. Power Electron., Vol. 23, No. 1, pp. 38-44, 2008

(3) Y. Xi, P. K. Jain, Y. F. Liu and R. Qrr, "A self core reset and zero voltage switching forward converter topology," IEEE Trans. Power Electron., vol. 15, no. 6, pp.1192-1203, 2003

(4) K. Soltanzadeh, M. Dehghani and H. Khalilian, "Analysis, design and implementation of an improved two-switch zero-current zero-voltage pulse-width modulation forward converter," IET. Power Electron., vol. 7, no. 4, pp.1016-1023, 2014

(5) G. Y. Jeon, "High efficiency asymmetrical half-bridge converter using a self-driven synchronous rectifier," IET. Power Electron., vol. 1, no. 1, pp.62-71, 2008

(6) R. T. Chen, Y. Y. Chen, and Y. R. Yang, "Single-stage asymmetrical half-bridge regulator with ripple reduction technique," IEEE Trans. Power Electron., vol. 23, no. 3, pp.1358-1369, 2008

(7) V. Meleshin and D. Ovchinnikoy, "Improved asymmetrical half-bridge converters," IEEE PEDS Proceedings, 2006, pp. 401-406

(8) C. T. Pan, C. F. Chuang, and C. C. Chu, "A novel transformerless interleaved high step-down conversion ratio dc-dc converter with low switch voltage stress," IEEE Trans. Industrial Electron., vol. 61, no. 10, pp.5290-5299, 2014

(9) J. Zhao and M. Sekine "A novel two-switch forward converter for high step-down conversion" IEEE INTELEC Proceedings, 2009, pp. 1-5

(10) M. Uno, "PWM switched capacitor voltage divider with high step-down ratio," IEEE PEDS Proceedings, 2013, pp. 1275-1279 